\title{
The Use of Geographic Information Systems (GIS) in Conducting a Needs Assessment of Seniors in Collier County
}

\section{Thomas Patrick Felke}

\begin{abstract}
Despite boasting a population where approximately $50 \%$ of individuals are aged 65 or older, Naples, Florida, has few services specifically targeting this population. This article reports on a project that utilized geographic information systems (GIS) to examine the current needs of the senior population in a defined section of Collier County, Florida. Various data points regarding the population age 65 and over were obtained using the U.S. Census Bureau's American FactFinder tool. These data were incorporated into digital maps that included the census tracts of the selected geographic area, locations of existing programs/services, and the existing transportation network. The results of the spatial analysis were corroborated by data collected via key informant interviews and focus groups. The result of the project was the establishment of the first senior access center in Collier County, FL. The project reinforces the use of GIS technologies for the purposes of needs assessment and siting program locations in the human services.
\end{abstract}

Keywords: Geographic information systems (GIS), seniors, needs assessment

Social work practitioners can employ geographic information systems (GIS) technologies for a variety of purposes, such as planning, monitoring, and evaluating of programs and services. This article describes a project in which GIS technologies were utilized as part of a community needs assessment focused on seniors in Collier County, Florida. The technologies merged existing descriptive data about the target population to a discrete geographic section of the county. Digital representations of the locations for existing services for seniors as well as a digital representation of the public transportation network assisted in identifying possible locations for the establishment of a senior access center within the county.

Whereas most projects employing GIS technologies have focused on ex post facto evaluation, this project utilized GIS technologies as a planning tool. The project centered on examining gaps in services to seniors and the identification of a site in Naples, FL with the best potential for establishing a senior access center. The project also included focus groups and key informant interviews in concert with GIS technologies in order to strengthen the analysis. This methodological approach is not one seen previously in the literature.

The Leadership Coalition on Aging for Collier County (LCA-CC), a partnership of community agencies working with the senior population, sought to commission a needs assessment to examine the specific needs of seniors in Collier County. Collier County is located in Southwest Florida, consists of approximately 2,300 square miles, and has an estimated population of over 330,000 residents (U.S. Census Bureau, 2013). The county includes three cities and nineteen unincorporated areas though the latter have local recognition as communities. One of these cities, Naples, has consistently ranked among the top three cities nationally having the most millionaires per capita (Kiplinger, 2014).

Dr. Thomas P. Felke is the BSW Program Coordinator and an Assistant Professor in the Department of Social Work at Florida Gulf Coast University. He focuses his research efforts on conducting community needs and assets assessments using community-based participatory research. He routinely teaches an elective course focused on the use of geographic information systems as a planning, research, and evaluation tool in the social services. (Email: tfelke@fgcu.edu) 
Despite this fact, local human service professionals and members of the LCA-CC knew that the events of the 2008 financial crisis had a significant impact on many individuals in Naples, particularly seniors. Based on their work with seniors in the local communities, members of the LCA-CC were interested in exploring the feasibility of establishing one or more access centers for seniors in Collier County. At the time, no single point of service access for seniors existed in Collier County. LCA-CC members felt this resulted in a lack of service coordination as well as sparse information regarding what services are available and to whom. Members identified four pre-existing locations in Collier County as having potential for being able to accommodate a senior access center but were uncertain which site was the best location or what specific services seniors most desired. This led to the development of the community needs assessment project described here. Due to his background with GIS technologies as a research instrument, the author was asked to participate in the project.

\section{GIS Applications}

GIS technologies are mapping tools used to create digital representations of key demographic variables according to desired geographic areas. A GIS is an organized collection of computer hardware, software, geographic data, and personnel designed to efficiently capture, store, update, manipulate, analyze, and display all forms of geographically referenced information (ESRI, 1992). These technologies allow the user to join quantitative data that includes a geographic reference with digital maps in order to display the data in a defined geographic space. The majority of descriptive data collected, maintained, and utilized in social work practice is geographically referenced information. This information provides details as to what may exist near, or even at, a specific location depending upon the level of spatial data. Spatial data, or digital representations of physical geography, are produced in several levels. These include but are not limited to state boundaries, city or town boundaries, zip code areas, census tracts, block groups, and streets. The following example illustrates the connection between descriptive and spatial data: When a social service agency collects a client's mailing address during an intake meeting, this data potentially contains several geographic references: the state, town, zip code, and street address where the client resides. Using a GIS, one can use descriptive data in combination with spatial data to create digital maps that symbolize what lies where. Further, the technologies provide tools for analyzing the geographically referenced data to identify patterns, understand spatial relationships, and detect trends (ESRI, 1992).

GIS technologies were first introduced in the 1960s for land use management. Today, they are used by practitioners from various backgrounds across an array of agencies for a variety of purposes. These technologies are employed at local, national, and international levels for purposes including disaster management (Amamoo-Otchere \& Akuetteh, 2005; Wood, 2000; Zakour \& Harrell, 2004), monitoring disease outbreaks (Ailes et al., 2014; Hershey et al., 2011; Idowu, 2011), and monitoring of refugee situations (Bjorgo, 2000; Kemper, Jenerowicz, Gueguen, Poli, \& Soille, 2011).

The application of GIS technologies first appeared in the social work literature in the late 1990s when Hoefer, Hoefer, and Tobias (1994) proposed GIS technologies as a potential tool for social workers to consider. Queralt and Witte $(1998,1999)$ undertook the 
earliest applications of utilizing GIS technologies to examine gaps in childcare service in areas of Massachusetts and Florida. The relevance of geography and, by extension, the application of GIS technologies for research and evaluation purposes has been explicated in the social work literature (Coulton, 2005; Felke, 2007; Hillier, 2007). As a result, the social work profession has seen an increase in the use of GIS technologies for a variety of planning and evaluation efforts (Friesthler, Lery, Gruenewald, \& Chow, 2006; Guerrero \& Kao, 2014; Leung \& Hanna, 2001; Wong \& Hillier, 2001).

GIS technologies have also been utilized to examine issues related to seniors. Hirshorn and Stewart (2003) believed that these technologies had largely been underutilized for gerontological research efforts between 1983 and 2000. However, a review of the recent literature suggests that efforts in this area have increased. For example, GIS technologies have been used to examine barriers in accessing services related to health and food insecurity (Lin, 2004; Ohta et al., 2007; Yamashita \& Kunkel, 2012). Though research on the topic is seemingly limited, GIS technologies have been used to ascertain ideal locations for the establishment of services to seniors. Carlson, York, and Primomo (2011) employed GIS technologies in this manner when identifying possible sites to deliver communitybased fall prevention program for older adults; the authors found GIS technologies were valuable in facilitating the selection of sites to maximize accessibility and utilization by targeted populations.

\section{Project Overview}

Faculty from the Department of Social Work at Florida Gulf Coast University (FGCU) was engaged to undertake the first ever needs assessment of seniors residing in Collier County. An initial meeting was held with LCA-CC members to outline the scope of the project and to define certain parameters. The spatial target area was one of the primary aspects of the study needing to be defined. While the LCA-CC was concerned with issues related to seniors throughout Collier County, it became apparent that the actual study area was smaller than the entire county itself. As a result, an area including the city of Naples and its immediate unincorporated border areas became the target geography for the needs assessment as shown in Figure 1. This decision was made after a discussion of the feasibility in attempting to focus on an area as large and disparate as Collier County.

Another important decision was the definition of a senior for the purposes of this project. Discussion among LCA-CC members centered on whether 60 or 65 years old should be established as the minimum age. In the end, the LCA-CC resolved to define a senior as an individual aged 65 years or older. This decision had only a minor impact on the data collected as the U.S. Census Bureau collects data for this population at both ages depending on variable. For example, data related to households receiving SNAP benefits is available for households including an individual aged 60 and older while data on individuals living alone is available for individuals aged 65 and over.

With insight from FGCU faculty, the LCA-CC sought to develop a comprehensive demographic profile of the senior population in the target geographic area to better understand the population as a whole. This was important as it was clear that a perception existed among some members of the LCA-CC that poverty was not an issue among the 
senior population. That was clearly reflected when, during an initial planning meeting to discuss possible variables, a LCA-CC member stated, "This is Naples. There are no poor people in Naples." The LCA-CC also sought to create a visual illustration of the senior population in relation to the existing public transportation network and human service providers. The primary purpose of this initiative was to develop an advocacy platform from which LCA-CC members could promote the expansion of the public transportation network to areas thought to be underserved. The final objective was to solicit feedback from human service professionals working with seniors and from members of the senior population regarding perceptions of senior needs in the target area. This was deemed important in order to ascertain whether the perceptions of the providers were in line with those of the seniors in the area.

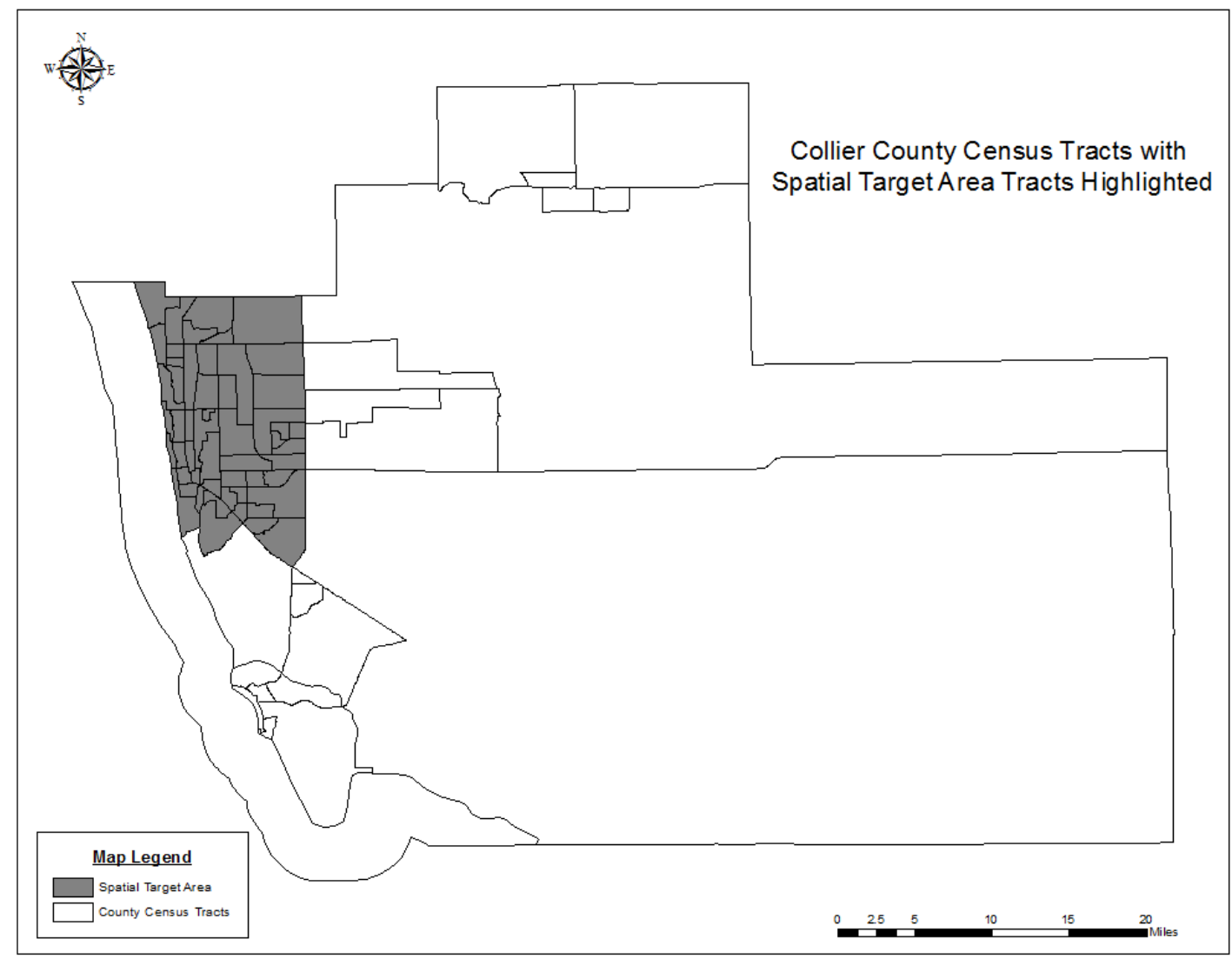

\section{Figure 1. Spatial Target Area}

Based on this and additional feedback gathered at the initial meeting, FGCU faculty began to formulate an assessment plan. They decided on a mixed methods approach because a quantitative component, including a spatial analysis using GIS technologies, would allow for the illustration of the target population in the selected geographic area while a qualitative component would allow for human service professionals, members of 
the target population, and other community stakeholders to lend voice to the quantitative data. The quantitative portion consisted of the analysis of existing data collected using the American Factfinder tool of the U.S. Census Bureau. The qualitative portion included key informant interviews with human service professionals working with the senior population in Collier County as well as focus groups with seniors residing in the county. Upon acceptance of the assessment plan by the LCA-CC, the project began in the summer of 2013.

\section{GIS Methodology}

While a mixed methods approach was developed, the primary focus of this article is the application of GIS technologies in this project. The primary purpose of this particular methodology was to illustrate the senior population in the geographic target area. As mentioned previously, the first step in this process was the development of an orientation basemap which was used to provide viewers with a geographic context of the spatial target area. A decision was made to collect data at the census tract level in order to provide an accurate illustration of the target population in the target geographic area. According to the U.S. Census Bureau (2012), census tracts "are small, relatively permanent statistical subdivisions of a county...generally have a population size between 1,200 and 8,000 people...to provide a stable set of geographic units for the presentation of statistical data" (para. 1). The general intention of Census tracts is to represent neighborhoods, as they are designed to be relatively homogeneous with respect to population characteristics, economic status, and living conditions (Iceland \& Steinmetz, 2003). As the target geographic area in this project consists of both incorporated and unincorporated areas, census tracts were deemed as the best spatial representation of the area.

To create a digital representation of the target geography, the author first obtained a digital map, or shapefile, of all census tracts in Collier County from the U.S. Census Bureau website. The author modified the census tract shapefile using ArcGIS (ESRI, 2011, version 10.1), a commercial GIS software program, to include only those tracts found in the target geography. The resultant shapefile included 53 census tracts from the initial set of 74 as shown previously in Figure 1.

A shapefile of the major road network of Collier County as well as a major highway, Interstate 75, were obtained from the Collier County GIS Services Division. These shapefiles were added to the ArcGIS project as overlays to the modified census tracts shapefile. The street network shapefile was modified through a process known as clipping so that it matched the borders of the census tract shapefile. The same modification process was undertaken on the shapefile of Interstate 75. To complete the digital representation of the area transportation network, two shapefiles of the public transportation system - one for the transit routes and one for the route stops - were obtained from the Collier County Metropolitan Planning Organization (MPO). The route shapefile was not included in the project file as it closely approximated the major road network. These shapefiles were also modified using the clip process outlined previously and then added to the ArcGIS project as overlays to the census tracts layer. 
A final layer of the identified site locations were also added to the project file. These locations were added through geocoding, a process of address interpolation whereby street address data is digitally represented as a point along a digital street network (ESRI, 2010). These layers were combined in the project file to create a basemap of the spatial target area as shown in Figure 2.

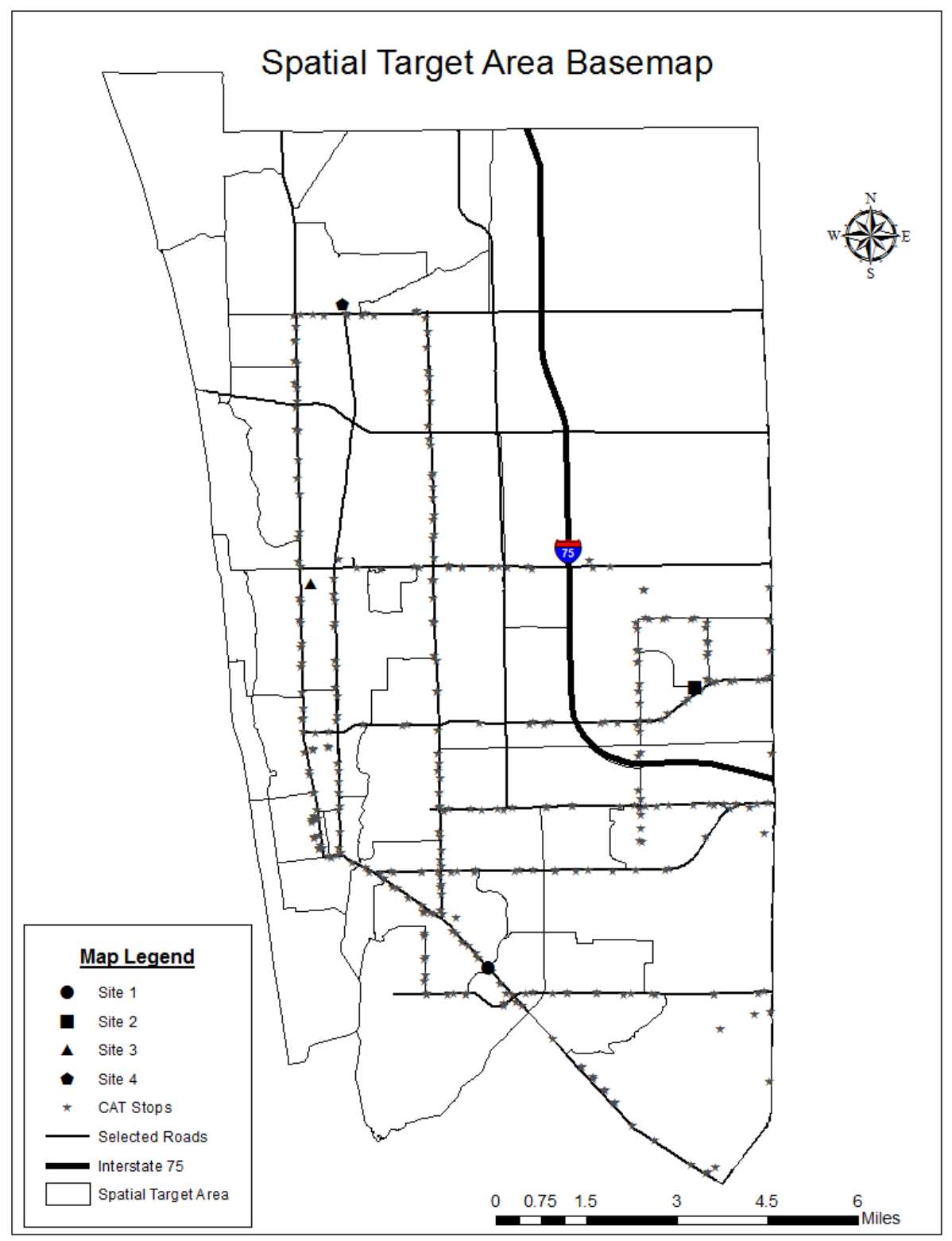

Figure 2. Spatial Target Area Basemap 
Once the spatial data set was modified and assembled, work began on building the descriptive dataset for the spatial target area. All descriptive data were obtained from the U.S. Census Bureau website using the American Factfinder tool. The author collected data from the 2012 American Community Survey (ACS) 5-year estimate dataset. The five-year estimates are a strong choice for use when analyzing very small populations such as at the census tract level (U.S. Census Bureau, 2013). A further rationale for the selection of this dataset was the availability of a broad range of age-specific variables. Using Microsoft Excel, the author compiled a comprehensive dataset along with a codebook containing descriptions of the variables and the tables from which they were drawn. The use of a Microsoft Excel workbook also allowed for the calculation of descriptive statistics and the creation of pivot tables used to view and present data in later presentations. The author ensured a unique identifier was included for each row of data, with each row representing a specific census tract found in the target area. This was done in order to create a join between the descriptive data for each census tract with its digital representation in the shapefile. This join between the table associated with the spatial data and the table holding the descriptive data is what allows for the visualization of the descriptive data on the digital map.

\section{Data Analysis}

The spatial data was first analyzed to locate key features and orient stakeholders to the reduced target area. A geoprocessing tool found in ArcMap was employed to locate the central feature, in this case the central census tract, of the target geographic area. This feature was located slightly east of center in the target area. This feature was both centrally located in the existing public transit system and home to one of the potential site locations for the Senior Center as shown in Figure 3.

The next step in the analysis was the visualization of the descriptive data that had been joined to the digital map. The author visualized each variable in the digital map using a basic count per census tract in order to identify the census tracts with the highest number of seniors according to each variable displayed. In the target geographic area, the senior population totaled approximately 58,000 individuals (48\% male; $52 \%$ female). The population was shown to be distributed with the largest concentrations in the northwest corner and central southern sections of the target area. A smaller but concentrated band of seniors was located in the target area near the centrally located site. While this map did not seem to have a major impact factor, the power of utilizing GIS technologies was apparent as, upon seeing the maps, several LCA-CC members remarked they were not aware the senior populations were located in certain areas. One member, upon seeing the close proximity between a large pocket of the senior population and their agency location, stated, "I had no idea that so many of them were right in my backyard."

Several demographic and socioeconomic variables were illustrated via GIS using basic counts in each census tract of the spatial target area. Within the target area, there were an estimated 2,470 households with a householder aged 65 years or older with income in the past 12 months below the federal poverty level. Spatially, the highest concentration of this population was located in the northeast corner of the target area with pockets also identified in the center and southeast corner. Additionally, there were approximately 1,200 
households with at least one resident aged 60 or older having received SNAP (Food Stamps) benefits in the past twelve months. Two pockets were identified with one being located in the northeast corner of the target area while the other was found near the central site location.

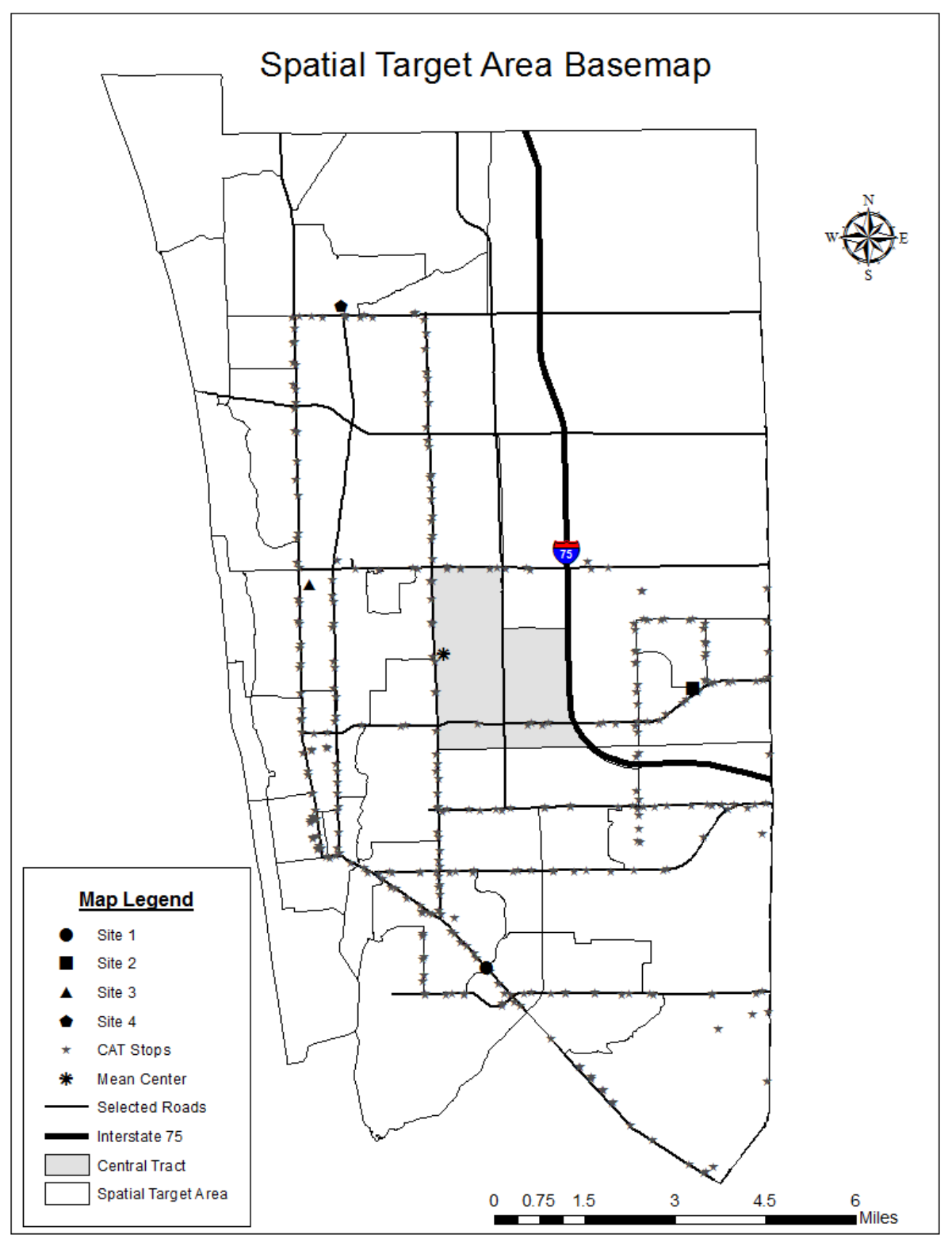

Figure 3. Central Features

One of the most important findings was the data regarding the number of households consisting of seniors living alone in the target area. The data showed that approximately 
16,600 individuals, roughly $29 \%$ of the total senior population, were living alone. There was almost double the number of senior women (66\%) than men (34\%) living alone. These populations were found to be distributed evenly throughout the target area with a few exceptions based on gender. The highest pocket of male seniors in this category was located in the southern area whereas three pockets of female seniors in this category were located in the central and northern areas. Taken as a whole, the highest densities were found near the central site location as well as on the northwest border. This variable took on the utmost importance as "lack of companionship" was the primary theme of the focus groups conducted with seniors in the target spatial area.

Using the total senior population by census tract as a base layer, a second geoprocessing tool was used to buffer the stops along the public transportation system. A buffer is an area of a pre-defined distance created around a map feature in order to conduct proximity analysis (ESRI, 2012). In this project, buffers of a quarter mile and a half-mile were created around the public transportation stops. These distances were selected based on walkability research among the elderly that identified these distances as the outer limits to which seniors will utilize public transportation (Hess, 2012; Kim \& Ulfarsson, 2004). An additional one mile buffer was added for comparative purposes. The proximity analysis found that none of the four site locations were particularly accessible for individuals utilizing the existing public transportation system as shown in Figure 4. In most cases, minimum walking distances between transit stops and site locations were in excess of one mile. Two locations were found to have at least one transit stop situated within a quartermile though only in one direction of the transit loop.

In summary, none of the four selected locations were located directly within a census tract with the highest population of individuals over 65, with the largest number of individuals below the federal poverty level, with the lowest median income, or with the largest number of household receiving SNAP benefits. Census tracts located in the northeast and northwest corners of the target area were found to contain high concentrations of seniors who might benefit from a senior access center. However, the lack of an available site location as well as limited public transportation were cited as major barriers for seniors residing in these areas. The centrally located site was in the closest proximity when evaluating the population according to each of these variables. This site was also the only location having a transit stop within a quarter-mile distance. Based on the findings of the spatial and proximity analyses, triangulated through data collected via the key informant interviews and focus groups, the author made a series of recommendations. Primary among the findings was the confirmation, despite public perception, that the target area was home to seniors with incomes below the poverty level and who lack access to needed services because of either transportation barriers or a lack of basic services for low-income individuals. The findings also showed a need, and want, for social activities and companionship among seniors.

Given its proximity to high senior populations based on the variables examined, the central site location was recommended for the establishment of a senior center with a second site located in the southeast corner, if feasible. A final recommendation was also made for the development and provision of alternate transportation options for seniors in 
the northeast and northwest corners of the target area so they might benefit from participation in a senior center.

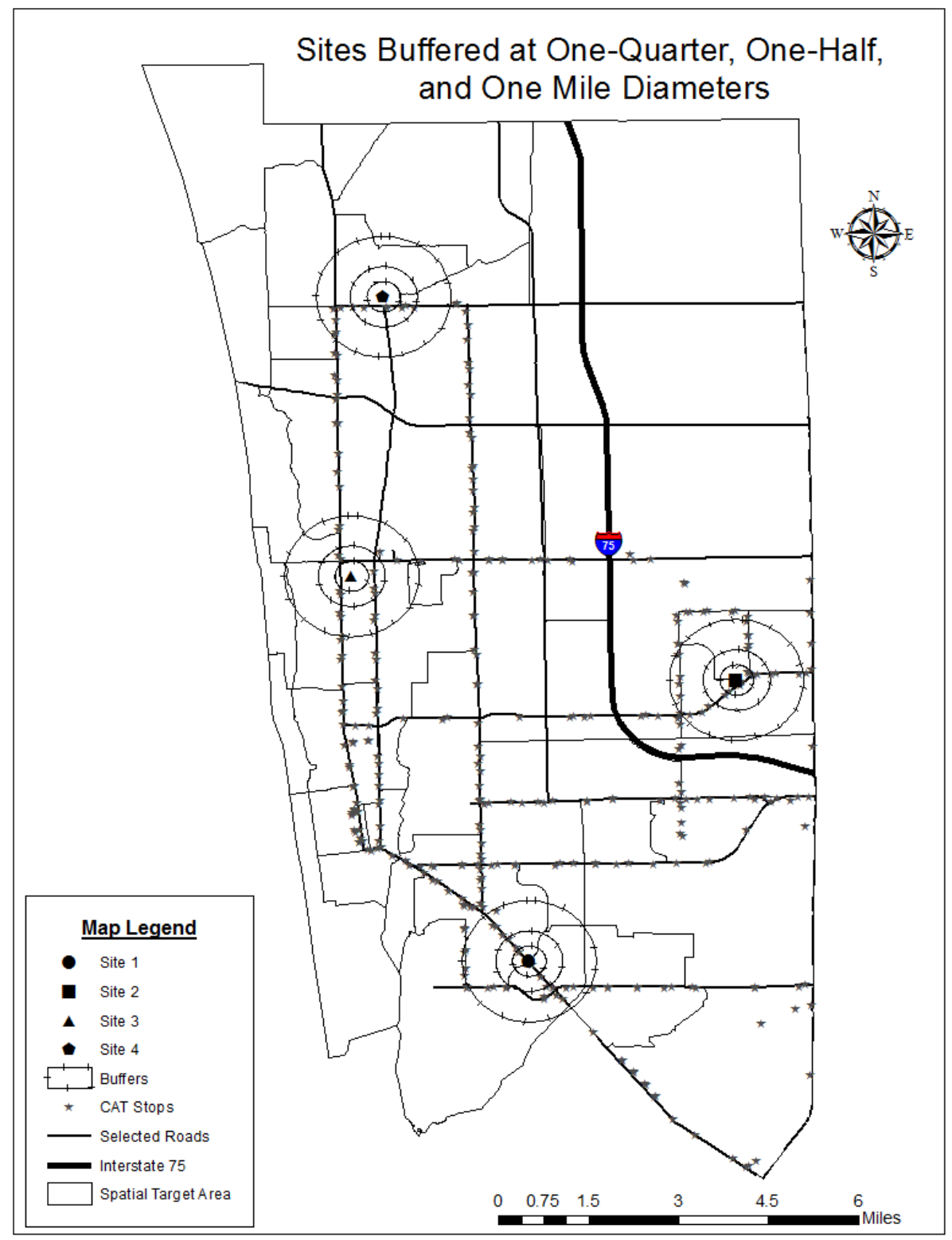

Figure 4. Site/Transportation Buffers

\section{Recommendations}

GIS technologies provide a tool that can be used for planning or evaluation purposes. The project described in this article focused on its use as a planning tool. The resultant 
maps provided a tangible product that allowed stakeholders to visualize the target population, according to various attributes, within the spatial target area. The maps also provided evidence that was difficult to refute and that ran contrary to prevailing opinions regarding the number of seniors in need in the spatial target area. By using GIS technologies, an optimal location for a senior access center was established, and some gaps for the senior population in the existing public transportation network were highlighted.

The incorporation of qualitative methodologies was a major benefit to this study. While the GIS technologies were able to provide a demographic illustration of seniors, it was the qualitative data that both supported and helped reframe the study along the way. Companionship was stated in the focus groups as the primary desire of seniors in establishing a senior access center. This was supported by the collected quantitative data showing a high number of seniors living alone in the spatial target area. This fact was corroborated in the key informant interviews with human service professionals who also noted a lack of access to transportation as a major barrier for seniors. However, the majority of seniors noted in the focus groups that this was not a primary issue for them as they did not rely on public transportation opting instead to either drive themselves or carpool with neighbors. Means of transportation was not included as a quantitative variable as the LCA$\mathrm{CC}$ members felt it was too obvious of a barrier to consider evaluating. In hindsight, given the feedback from the focus groups, it might have been a very useful variable to examine.

It is important to take into consideration the understanding of the stakeholder group of both available data and GIS technologies. LCA-CC members often questioned the use of the dataset being utilized, not in terms of its accuracy, but availability. Members felt that data such as that used in this project should have been available more frequently and been collected locally. Educating members on the complexities of data collection and management, even for the comparatively small spatial target area in this project, became an important task in order to develop confidence in the process. It was also important to educate members on the capabilities of GIS technologies. While many members felt they understood what the technologies could be used for, it became clear in preliminary discussions that this knowledge was actually limited. Some members felt the technology was, and would be, used to track the target population while others would routinely confuse GIS and GPS (global positioning systems) technologies both in name and function.

\section{Conclusion}

Based on the project findings outlined in this article, funding was obtained to establish the first senior access center in Collier County. The 4,000-square-foot center opened in January 2014 with a plan to operate a weekly congregate luncheon and occasional social activities for seniors. Due to a tremendous response from seniors in the Naples community and adjoining areas, the Center now operates on a daily basis, serving approximately 450 local seniors. Initial analysis of the participant demographics, as well as direct feedback from seniors, has found that the center is meeting the needs identified in the study. GIS technologies are now being used as an evaluative tool for this purpose with a spatial analysis showing that participants are from the areas identified as having high concentrations of seniors living alone as well as areas with high numbers of seniors living below the poverty line. The county transit department noted the recommendations 
concerning transportation preferences as reported in the focus groups. Public transportation was expanded to areas with high concentrations of seniors through deviations in the fixed route transit system and expansion of ride share services, which allow seniors to attend activities without the need to walk extended distances or ride traditional public transit routes that include multiple stops and/or circuitous routes.

The opening of second center is planned in the southeast corner of the target area by the end of 2014 using the results of this project as a basis for its establishment. The second location is being sited based on recommendations produced through the spatial analysis.

Moreover, neighboring communities have recognized the value in utilizing GIS technologies as a tool in conducting community needs assessments. The author has been contacted by organizations in two neighboring counties who are seeking to utilize GIS technologies as part of their needs assessment and planning efforts. One effort will focus on future parks and recreation planning while the second will be aimed at identifying and prioritizing community needs in a currently unincorporated area seeking to become incorporated. The practical application of GIS technologies is evident and will hopefully continue to gain visibility as a tool for the social work practitioner.

\section{References}

Ailes, E., Newsome, K., Williams, J., McIntyre, A., Jamieson, D., Finelli, L., \& Honein, M. (2014). CDC pregnancy flu line: Monitoring severe illness among pregnant women with influenza. Maternal and Child Health Journal, 18(7), 1578-1582.

Amamoo-Otechere, E., \& Akuetteh, B. (2005). Building disaster anticipation information into the Ghana development and poverty mapping and monitoring system. In P. van Oosterom, S. Zlatanova, \& E. M. Fendel (Eds.), Geo-information for disaster management (pp. 809-818). Berlin: Springer-Verlag.

Bjorgo, E. (2000). Refugee camp mapping using very high spatial resolution satellite sensor images. Geocarto International, 15(2), 79-88.

Carlson, T., York, S., \& Primomo, J. (2011). The utilization of geographic information systems to create a site selection strategy to disseminate an older adult fall prevention program. The Social Science Journal, 48(1), 159-174.

Coulton, C. (2005). The place of community in social work practice research: Conceptual and methodological developments. Social Work Research, 29(2), 73-86.

ESRI. (1992). The ARC/INFO Method. Redlands, CA: Environmental Systems Research Institute.

ESRI. (2010). What is geocoding? Retrieved from http://help.arcgis.com/en/arcgisdesktop/10.0/help/index.html\#//00250000000100000 0.htm

ESRI. (2011). ArcGIS for Desktop (Version 10.1) [Software]. Available from http://www.esri.com/software/arcgis/arcgis-for-desktop 
ESRI. (2012). Buffer (Analysis). Retrieved from http://help.arcgis.com/en/arcgisdesktop/10.0/help/index.html\#//00080000001900000 0

Felke, T. (2007). Geographic information systems: Potential uses in social work education and practice. Journal of Evidence-based Social Work Practice, 3(3/4), 103113.

Friesthler, B., Lery, B., Gruenewald, P. J., \& Chow, J. (2006). Methods and challenges of analyzing spatial data for social work problems. Social Work Research, 30(4), 198210.

Guerrero, E., \& Kao, D. (2014, January). Access to integrated care in substance abuse treatment: Travel distance from low income and diverse communities. Paper presented at the annual conference of the Society for Social Work and Research, San Antonio, TX.

Hershey, C. L., Doocy, S., Anderson, J., Haskew, C., Spiegel, P., \& Moss, W. J. (2011). Incidence and risk factors for malaria, pneumonia, and diarrhea in children under 5 in UNHCR refugee camps: A retrospective study. Conflict and Health, 5, 24-33.

Hess, D. (2012). Walking to the bust stop: Perceived versus actual walking distance to bus stops for older adults. Transportation, 39(2), 247-266.

Hillier, A. (2007). Why social work needs mapping. Journal of Social Work Education, 43(2), 205-221.

Hirshorn, B., \& Stewart, J. (2003). Geographic information systems in community-based gerontological research and practice, Journal of Applied Gerontology, 22(1), 134151.

Hoefer, R. A., Hoefer, R., \& Tobias, R. A. (1994). Geographic information systems and human services. Journal of Community Practice, 1, 113-128.

Iceland, J., \& Steinmetz, E. (2003). The effects of using census block groups instead of census tracts when examining residential housing patterns. Racial and ethnic residential segregation in the United States: 1980-2000. U.S. Census Bureau, Census Special Report, CENSR-3, Washington, DC: U.S. Government Printing Office.

Idowu, P. (2011). A GIS data model for disease surveillance and monitoring: Nigeria as a case study. Saarbrücken, Germany: Lambert Academic Publishing.

Kemper, T., Jenerowicz, M., Gueguen, L., Poli, D., \& Soille, P. (2011). Monitoring changes in the Menik Farm IDP camps in Sri Lanka using multi-temporal very highresolution satellite data. International Journal of Digital Earth, 4(1), 91-106.

Kim S., \& Ulfarsson, G. (2004). Travel mode choice of the elderly: Effects of personal, household, neighborhood, and trip characteristics. Transportation Research Record, 1894, 117-126. 
Kiplinger. (2014). Where millionaires live in America. Retrieved from http://www.kiplinger.com/slideshow/real-estate/T010-S001-where-millionaires-livein-america-slide-show/index.html

Leung, C. K., \& Hanna, M. (2001). Improving human service planning with ArcView: An exploratory study of childcare stability and utilization. Paper presented at the ESRI International Users Conference, San Diego, CA. Retrieved from http://gis.esri.com/library/userconf/proc00/professional/papers/PAP168/p168.htm

Lin, S. (2004). Access to community pharmacies by the elderly in Illinois: A geographic information systems analysis. Journal of Medical Systems, 28(3), 301-309.

Ohta, K., Kobashi, G., Takano, S., Kagaya, S., Yamada, H., Minakami, H., \& Yamamura, E. (2007). Analysis of the geographical accessibility of neurosurgical emergency hospitals in Sapporo city using GIS and AHP. International Journal of Geographical Information Science, 21(6), 687-698.

Queralt, M., \& Witte, A. D. (1998). A map for you? Geographic information systems in the social services. Social Work, 43(5), 455-469.

Queralt, M., \& Witte, A. D. (1999). Estimating unmet need for services: A middling approach. Social Service Review, 73, 524-559.

U.S. Census Bureau. (2012). Geographic terms and concepts - census tract. Retrieved from https://www.census.gov/geo/reference/gtc/gtc_ct.html

U.S. Census Bureau. (2013). American Community Survey 3-year estimates - Collier County, Florida census tracts. Retrieved from http://factfinder.census.gov/faces/nav/jsf/pages/searchresults.xhtml?refresh=t

Wong, Y. I., \& Hillier, A. (2001). Evaluating a community-based homelessness prevention program: A geographic information system approach. Administration in Social Work, 25(4), 21-45.

Wood, W. (2000). Complex emergency response planning and coordination: Potential GIS applications. Geopolitics, 5(1), 19-36.

Yamashita, T., \& Kunkel, S. (2012). Geographic access to healthy and unhealthy foods for the older population in a U.S. metropolitan area. Journal of Applied Gerontology, 31(3), 287-313.

Zakour, M., \& Harrell, E. (2004). Access to disaster services: Social work interventions for vulnerable populations. Journal of Social Service Research, 30(2), 27-54. 